\title{
Influjo de escritores europeos, en la comedia de Fernando Calderón "A ninguna de las tres"
}

Nada de lo que dice el doctor Francisco. Monterde, en su "estudio preliminar" de la edición de la Imprenta Universitaria (1943) de $A$ ninguna de las tres, es nuestra intención repetir aquí, porque todo lo ha realizado con mucho acierto: análisis de los personajes de Marcela de Bretón de los Herreros y de los de $A$ ninguna de las tres; comparación y demás observaciones. Creemos, sin embargo, que caben unas cuantas palabras, respecto a lo que hizo Calderón con el plan general sugerido por Marcela, para darnos la comedia que nos dió.

Aparte de que el buen trazo de los caracteres pertenezca a la habilidad dramática de Calderón (esto no quiere decir que no la tuviera Bretón); de aquello que corresponda a los resortes dramáticos, a la atinada pintura o crítica de ciertas costumbres de la época, ¿qué más se ve en esta obra de Calderón? En primer lugar, se sabe que Calderón fué uno de los primeros románticos mexicanos y que en esta comedia critica el mismo romántico ciertos excesos del romanticismo. En este punto no podemos menos de acordarnos de Cervantes, porque dicen que tuvo la intención, al escribir su obra maestra, de dar muerte a los libros de caballería que sacaban a las gentes de quicio, porque leyendo estos libros se pasaban "las noches de claro en claro y los días de turbio en turbio"; y luego nos dejó el propio Cervantes el mejor de los libros de su especie.

No queremos decir que Calderón tuviera la misma intención que Cervantes, ni que nos dejara la mejor obra romántica; pero sí 
queremos decir que, al criticar el romanticismo, dió una comedia muy a la romántica, con sus caracteres vívidos y bien delineados. Según nuestra manera de pensar, el interés de la comedia estriba en lo que en ella se ve, que es mucho, de la corriente romántica. Léanse las obras románticas de la época; léanse los periódicos y revistas románticos, como El Artista y El Semanario Pintoresco Español -y no se dejen de leer los artículos de Mesonero Romanos, como "E1 romanticismo y los románticos"- y se verá que cuanto más se sabe de la literatura de la época, tanto más se comprende y se aprecia esta obra de Calderón, porque mejor se la sitúa en el ambiente a que pertenece. Aun se diría que los caracteres tan bien delineados que se ven en la obra, se identifican con personajes bien conocidos o fáciles de imaginar según las obras aludidas y mencionadas.

Creemos, pues, que $A$ ninguna de las tres, como las otras obras dramáticas del autor, refleja las lecturas del propio dramaturgo, en la literatura europea; y ahora no nos referimos a Marcela; esta obra, aunque modelo, la consideramos simplemente como punto de partida. De ella se sirvió Calderón, a manera de referencia, para darnos más literatura de carácter romántico o para darnos más reflejos de sus lecturas. De esto hay mucho en la obra. Si, por ejemplo, Marcela dice, a manera de lisonja, que Agapito, uno de sus pretendientes, (I, 1) baila con tanta gracia que basta para hacerse dueño del más yerto corazón, Calderón le da mayor objetividad, al hacer que Timoteo diga $(I, 1)$ :

\author{
No; pero nada, Serapia, \\ como el "campestre" : me acuerdo \\ que estaba yo como tonto, \\ mirando tus movimientos; \\ desde la primera parte, \\ sentí dentro de mi pecho \\ cierta inquietud... cierta cosa... \\ lo que llaman los modernos \\ simpatía; pero ivaya! \\ cuando hizo tu pie derecho \\ aquel molinete, entonces \\ se me trastornó el cerebro. \\ ¡Ah! ¡y qué noche me diste!
}

Todo lo cual tiene un tono de sinceridad que no se encuentra en lo que dice Marcela. Timoteo habla con su mujer de incidentes acaeci- 
dos allá en los tiempos muy lejanos de su noviazgo; Marcela habla, coqueta, con uno de sus pretendientes que luego rechaza. A esta sinceridad la llamarían los románticos "verdad", "algo del corazón". Además, esta cita nos recuerda, no Marcela, sino Die Leiden des junges Werthers, libro r, 16 de junio:

Lotte und ihr Tänzer fingen einen Englischen an, und wie wohl mir's war, als sie auch in der Reihe die Figur mit uns anfing, magst du fühlen. Tanzen muss man sie sehen! Siehst du, sie ist so mit ganzer Herzen und mit ganzer Seele dabei, ihr ganzer Körper eine Harmonie, so sorglos, so unbefangen, als wenn das eigentlich alles wäre, als wenn sie sonst nichts dächte, nichts empfände.

Más parecidos se encuentran con Werther que con Marcela, en otros casos: la preferida por don Amadeo, el poeta, Marcela misma, II, 4 :

es de las gracias modelo,...

En A ninguna de las tres, I, 3, Mariquita:

...en fin es un modelo

de perfección...

En Werther, libro I, junio 16, Lotte es

Einen Engel! ... Und doch bin ich nicht im stande, dir zu sagen, wie sie vollkommen ist, warum sie vollkommen ist; genug, sie hat allen meinen Sinn gefangen genommen.

Y cuando don Carlos ( $\mathbf{I r}, 4)$ simula estar enamorado de Leonor, y dice :

En mi fantasía

está usted en todas partes:

en las calles, en la Viga,

la Alameda, Bucareli,

en el Portal; hasta en misa,

me parece que estoy viendo

esa mirada divina,

nos recuerda a Werther, por el tono que predomina, cuando éste dice de Lotte, libro II, 6 de diciembre: 
Wie mich die Gestalt verfolgt! Wachend und traumend füllt sie meine ganze Seele! Hier, wenn ich die Augen schliesse, hier in meiner Stirne, wo die innere Sehkraft sich vereinigt stehen ihre schwarzen Augen. Hier! ich kann dir's nicht ausdrücken.

Tanto como de Werther, creemos ver paráfrasis de Julie ou la Nouvelle Eloise, de Rousseau, en más de una ocasión.

En ciertos casos las lecturas que creemos ver reflejadas en $A$ ninguna de las tres, no son de las clasificadas como "románticas". ¿Queremos, por ejemplo, que nos describa el padre Isla, allá por los años 1758-1770, al don Carlos de $A$ ninguna de las tres? Notemos que el afrancesado de Fray Gerundio de Campazas, libro Iv, capituJo VIII se llama también "don Carlos":

Llamábase D. Carlos el sugeto de esta historia, y como por una parte no era del todo lerdo, y por otra había estado tan despacio en Madrid,... (el don Carlos mexicano había estado tan despacio en México) se le había pegado fuertemente el aire de la gran moda; hacía cortesías a la francesa, hablaba en español del mismo modo, afectando los rodeos del francesismo y hasta el mismo modo, dialecto y retintín con que lo hablan los de aquella nación. ... en fin, nuestro D. Carlos parecía un monsieur hecho y derecho, y por lo que tocaba a él, de buena gana trocaría por un monsieur todos los dones y turuleques del mundo, tanto, que hasta los dones del Espíritu Santo le sonarían mejor, y acaso les solicitaría con mayor empeño, si se llamasen monsieures.

La muy inculta de doña Serapia, que dice que en el teatro coetáneo rige un tal "Fugo", etc., etc., no deja de recordarnos la misma obra del padre Isla, por el "bonazo del tío Antón Zotes", que dice engenio, copras, dende, emprea, ansina, golver, etc.

¿Queremos ahora que Larra nos sugiera a don Antonio, el "muy mexicano" de A ninguna de las tres? Braulio, en "El castellano viejo",

... Es tal su patriotismo que dará todas las lindezas del extranjero por un dedo de su país...

Este artículo de Larra nos recuerda otros incidentes de $A$ ninguna de las tres: Braulio, como don Timoteo, celebra su cumpleaños; Braulio, como don Timoteo a don Antonio, invita a Larra a comer; Larra 
no quiere quedarse a la comida, pero al fin condesciende: así don Antonio. Más Larra creemos ver en que don Timoteo quiera que don Juan, hijo de un amigo antiguo suyo, se case con una de sus hijas. En No más mostrador I, 4, quiere don Deogracias que Bernardo, hijo de uno de sus amigos, se case con su hija, Julia. ¿ No vèmos, además, algunas de las características de nuestro petimetre don Carlos, en lo que don Deogracias aconseja a Bernardo?

¿Quién sabe si la primera impresión...? En fin, es preciso que se vaya usted a vestir, que venga (a conocer a Julia) usted haciendo muchos gestos, muchos ascos, muchas contorsiones; que hable usted algo de francés, algo de italiano, español poco y mal, y siempre sin fundamento, que baile, que... hable mucho de la ópera y de París y si puede ser de Londres.

Todo esto hace don Carlos, y más. ¿̨ Se desea otro ejemplo?

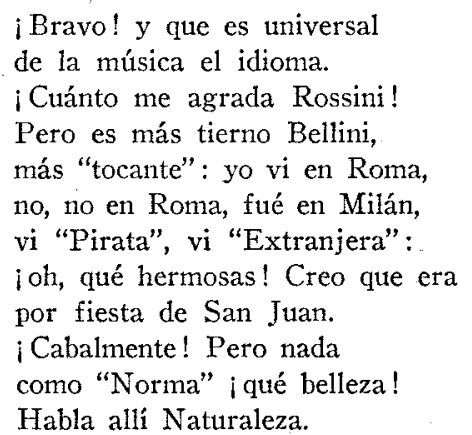

$$
\text { I, } 4 .
$$

Hemos dicho antes que esta obra de Calderón nos recuerda artículos de revistas románticas españolas, como El Artista y El Semanario Pintoresco. (Algunas revistas mexicanas de la época seguían la tendencia de las europeas.) María, por ejemplo, nos recuerda - como pudo recordar a Calderón a alguna conocida suya- "Una mujer a la moda" en El Semanario Pintoresco, 1836, páginas 209210:

La primera necesidad de una mujer a la moda es producir efecto $;. .$. E1 secreto consiste ell elegir objetos extraordinarios pero que la vayan bien... Unia mujer a la moda, subyugada por la idea de 
agradar indistintamente, guardada por la elegante frialdad de su corazón, podría permanecer intachable toda su vida, si el principal deber de la mujer a la moda no fuese sujetar a su carro al hombre a la moda; por desgracia el primer deber de este hombre es el de seducir a la moda... (¿ No se ve aquí al seductor don Carlos de $A$ ninguna de las tres?).

Cuando don Timoteo corrige a doña Serapia, por haber dicho "Fugo", ( $, 1,1)$ responde ella:

$$
\begin{aligned}
& \text { ¿Yo qué entiendo } \\
& \text { de esos nombres que no estát1 } \\
& \text { en el calendario nuestro? } \\
& \text { Hasta en eso entró la moda: } \\
& \text { a nadie le ponen Diego, } \\
& \text { ni Jacinto, ni Macario,... } \\
& \text { ni Roque, ni Timoteo; } \\
& \text { sino Arepo, Arturo, Adolfo; } \\
& \text { en fin, santos extranjeros } \\
& \text { que ni están bautizados... }
\end{aligned}
$$

En el artículo arriba citado de El Semanario Pintoresco, se lee:

'Yo quisiera tener dos niñas (dice): las hubiera puesto nombres románticos, cantábiles, Niobe, Ceferina, Venturina, Amalthea.' (Habla la mujer a la moda.)

Literariamente, que don Timoteo y su mujer inicien la obra comparando la generación actual con la precedente, nos recuerda la polémica literaria y costumbrista tan bien conocida en la literatura española, entre 1830 y 1840 . Léanse los artículos de crítica literaria de Larra y los de Mesonero Romanos, por ejemplo. Léanse, repetimos, los periódicos de la época y se verá a primera vista, aun en las láminas, el reflejo de lo que ahora escribimos: "El pastor clasiquino": El Artista, I, p. 229; "Antaño": El Artista, Ir, p. 114; "Un romántico": El Artista, I, p. 28, que reproduce Díaz-Plaja en su Introducción al romanticismo español; "Hogaño": El Artista, Ir, p. 120...

Lo repetimos: Marcela sirvió de modelo para $A$ ninguna de las tres; pero sólo a manera de bosquejo que el autor mexicano completó entreverando incidentes: unos, sacados de su propia invención; otros, de la sociedad en que vivía, y otros, de la literatura que leía. ¿Cuál de estos tres elementos sería el mayor? Pues, por lo menos 
se dirá que tantos de los incidentes, o ideas, o caracteres, aun los bien delineados, pertenecen a la literatura romántica, sobre todo a la española y la francesa, que tratar de fijar el origen de todos ellos en esas literaturas, nos remontaría a lo más prolijo, a lo absurdo.

Pablo Avila, University of California, Santa Barbara College, Santa Barbara, California. 
